\title{
Factors associated with dietary practice and nutritional status of pregnant women in Dessie town, northeastern Ethiopia: a community-based cross-sectional study
}

\author{
Tona Zema Diddana(1)
}

\begin{abstract}
Background: Maternal undernutrition is highly prevalent in resource-poor settings. Hence, this study was intended to determine factors associated with the dietary practice and nutritional status of pregnant women in Dessie town, northeastern Ethiopia.

Methods: Community-based cross-sectional study design was employed. Six hundred four (604) pregnant women have participated. A two-stage sampling method was applied to select participants. Socio-demographic and socio-economic data were collected using a structured interviewer-administered questionnaire. The dietary practice was measured using 13 dietary practice questions. Mid upper arm circumference (MUAC) was measured by standard nonstretchable MUAC tape. Data were entered into Epi-Info 7 and exported to SPSS version 20. Binary and multiple logistic regression analysis was conducted. Variables with $P<0.2$ in bivariate analysis were entered for multiple logistic regression. At a 95\% confidence interval, variable with $\quad<0.05$ in multiple logistic regression analysis was considered statistically significant.
\end{abstract}

Result: About $54.8 \%$ of the pregnant women had poor dietary practice and $19.5 \%$ were undernourished. First trimester of pregnancy ( $A O R=0.46 ; 95 \% \mathrm{Cl}: 0.26,0.80$ ), no history of illness 2 weeks before data collection date $(A O R=0.42 ; 95 \% \mathrm{Cl}: 0.22,0.80)$, poor perceived severity $(A O R=1.64 ; 95 \% \mathrm{Cl}: 1.15,2.33)$, poor perceived benefits ( $A O R=1.63 ; 95 \% \mathrm{Cl}: 1.14,2.32)$ and poor self efficacy ( $A O R=4.74 ; 95 \% \mathrm{Cl}: 2.94,7.65)$ were significantly associated with poor dietary practice. Not attending antenatal care (ANC) (AOR $=3.46$; $95 \%$ Cl: 2.07, 5.78), illness (AOR $=1.93 ; 95 \% \mathrm{Cl}: 1.10,3.5)$, poor dietary diversity ( $A O R=5.92 ; 95 \% \mathrm{Cl}: 3.59,9.76)$, poor nutrition knowledge ( $A O R=3.03 ; 95 \% \mathrm{Cl}: 1.87,4.92)$, poor dietary practice $(A O R=3.25 ; 95 \% \mathrm{Cl}: 1.91,5.54)$ and poor perceived self efficacy $(A O R=5.59 ; 95 \% \mathrm{Cl}: 3.56,8.79)$ were significantly associated $(P<0.05)$ with undernutrition.

Conclusion: The dietary practice of pregnant women was suboptimal and nutritional status was relatively high. Being in the first trimester of pregnancy and no history illness were negatively associated while poorly perceived severity to malnutrition, poor perceived benefits, and poor self-efficacy were positively associated with the poor dietary practice. Not attending ANC, history of illness, poor dietary diversity, poor nutritional knowledge, poor dietary practice, poorly perceived self-efficacy were positively associated with undernutrition. Government, health extension workers and other concerned bodies should encourage pregnant women to attend ANC, promote health during pregnancy, strength and counsel to improve dietary diversity and practice of good nutrition. They should focus on the perceived belief of dietary behaviors.

Keywords: Dietary diversity, Nutritional status, Pregnant women, Ethiopia 


\section{Background}

Nutrition throughout the life cycle has a major impact on health. This is true for pregnant women as pregnancy is the most nutritionally demanding period in their life. Undernutrition and failure to receive essential nutrients in both quality and quantity during this physiologically demanding period would result in adverse pregnancy outcomes [1]. Undernourished mothers are more vulnerable to diseases, encounter more miscarriages and give birth to underweight children whose survival is at risk $[2,3]$. Poor nutrition during pregnancy also contributes to the low weight gain of the mother, which is risk factors for the delivery of infants too small for gestational age leading to neonatal mortality and morbidity [4], failure to grow, slow cognitive development and chronic diseases in adulthood [5].

Globally, an estimated 15 million babies are born preterm [6] and about 20 million are born with low birth weight. More than $95 \%$ of these births are occurring in resource-poor countries [7]. Ethiopia is one of the developing nations with a high burden of maternal and child undernutrition, morbidity and mortality. The 2016 Ethiopian demographic and health survey (EDHS) report indicated that $22.4 \%$ of women's reproductive ages (15-49 years) were undernourished and $29 \%$ were anemic at the national level. The prevalence of undernutrition was $22.9 \%$ in the Amhara region, the area where this study is conducted [8]. Pieces of evidence from local surveys in Ethiopia illustrated that undernutrition among pregnant women varies from $15.2-35.5 \%$ [9-11], and poor dietary practice women range from 39.3-66.1\% [9, 12 and 13].

Inappropriate nutrition practice due to the wrong perception in combination with environmental and socioeconomic factors and infections are common causes of maternal undernutrition and mortality, low birth weight and intergrowth retardation [12]. A study conducted in northwestern Ethiopia indicated that attitude towards specific dietary habits, exposure to nutrition information; maternal education; income and nutritional knowledge were predictors of the dietary practice [13]. Another study from Bahir dar town, Ethiopia, showed that not taking iron supplements, lack of radio/television, husband's income, maternal age and poor nutrition knowledge were factors for poor dietary practice [9]. Another study conducted in Shashemene district, Ethiopia, discovered that following antenatal care significantly associated with maternal dietary practice [12]. Similarly, age at first marriage and meal frequency [14], educational status [15], occupation of the head of household and religion [16], marital status [15, 16] was discovered as risk factors for undernutrition among pregnant women. Risk factors for maternal dietary practice and undernutrition might not be the same across different regions due to differences in socioeconomic characteristics, culture, ethnicity and geographical location. Furthermore, there is a literature gap on the dietary practice and nutritional status of pregnant women in the Dessie area. Hence, identifying community-based specific factors affecting maternal dietary practice and nutritional status is necessary and critical to design appropriate interventions. Hence, this study was conducted to determine factors associated with dietary practice and the nutritional status of pregnant women in Dessie town, Northeastern Ethiopia, 2017 G.C.

\section{Methods}

\section{Description of the study area}

This study was conducted in Dessie town, northeastern Ethiopia. The town is located in Amhara Regional State, northeastern Ethiopia. It is $401 \mathrm{Km}$ away from the capital city, Addis Ababa and $475 \mathrm{Km}$ away from the regional city, Bahirdar.

\section{Study design and study period}

A community-based cross-sectional study was conducted in July 2017 G.C.

\section{Source population and study population}

The source population of this study was pregnant women who were resided for at least 6 months in the town during the study period. The study population was pregnant women who were randomly selected from studied kebeles and included in this study.

\section{Sample size determination}

The sample size was determined using a single population proportion formula indicated below. Prevalence of poor dietary practice among pregnant $(P=60.7 \%)$ in northwestern Ethiopia was taken to estimate sample size [9]. Margin of error (0.05), critical value at 95\% confidence interval $(\mathrm{Z1}-\quad / 2=1.96)$ and design effect $(\mathrm{DE})=$ 1.5 was used. 10 percent (10\%) non-response rate was added. Finally, 604 pregnant women were included in this study.

$$
n=\frac{\left(Z_{1-\frac{a}{2}}\right)^{2} * p *(1-P)}{d^{2}}
$$

\section{Sampling procedure and technique}

A two-stage sampling technique was used. At the first stage, four sub-cities among 10 were selected using the lottery method. The lists of pregnant women (sampling frame) living in these four sub-cities were obtained. In the second stage, participants from each kebeles were selected proportionally by using a simple random sampling technique. 


\section{Inclusion and exclusion criteria}

All pregnant women who were lived for at least 6 months in the town and healthy (self-reported) were included. Pregnant women with disability (unable to speak) at the time of data collection were excluded.

\section{Variables}

\section{Dependent variables}

Dietary practice and nutritional status of pregnant women.

\section{Independent variables}

Socio-economic and socio-demographic factors, obstetric and pregnancy-related factors, stage of pregnancy, nutrition knowledge, morbidity, dietary diversity, antenatal care (ANC) attendance and health belief model constructs (perceived severity, susceptibility, benefits, barriers, and self-efficacy).

\section{Data collection tools and procedures}

Data were collected using a structured intervieweradministered questionnaire by eight trained nutrition professionals through the house to house visiting. Socioeconomic and socio-demographic factors, health belief model constructs, nutrition knowledge, dietary practice, and anthropometric data were collected.

Sociodemographic and economic data were collected using a structured questionnaire adapted from the Ethiopian demographic and health survey EDHS (2016) [8]. Items of Health Belief Model constructs were measured using a five-point Likert scale $(5=$ strongly agree to $1=$ strongly disagree). Then, the value of each Likert scale scored by participants for each question was summed and the mean was calculated.

Dietary diversity was collected using 10 food groups recommended by the food and agriculture organization of the United Nations (FAO). Based on FAO cut of points, dietary diversity is poor if less than five food groups consumed 24-h before the date of data collection; and good if a woman ate at least five food groups in the past 24-h before the date of data collection [17].

Nutrition knowledge was collected using 15 nutrition knowledge questions. Nutrition knowledge score was calculated by conducting factor analysis to reduce data and identify nutrition knowledge that explained most of the variance. Then, the nutrition knowledge responses that showed high variation in factor analysis were summed and the average (mean) was calculated.

The dietary practice was assessed using 13 dietary habit questions. The dietary practice score was obtained by summing each response given by participants. Participants were given score 1 if they correctly answer the question, favorable or healthy for dietary practice, and score 0 , if they did not correctly answer the question, not favorable or healthy for dietary practice.

Nutritional status was determined by measuring middle upper arm circumference (MUAC). MUAC of the left arm was measured triplicate using a nonstretchable standard MUAC tape to the nearest $0.1 \mathrm{~cm}$ with no clothing on the arm. The average of triplicate measurement was taken. Pregnant women having MUAC $<23 \mathrm{~cm}$ were considered undernourished and $\geq 23 \mathrm{~cm}$ normal [18].

\section{Data quality assurance}

A questionnaire was first prepared in English and then translated to the local language called Amharic. The training was given for data collectors and supervisors on methods of obtaining consent, study objectives, contents of the questionnaire, interviewing technique and MUAC measurement procedures. A pretest was conducted on $10 \%$ of the total sample size on pregnant women living in the area other than the study site. MUAC measurement was taken in triplicate to ensure accuracy. Overall data collection was monitored daily and the questionnaire was checked for completeness and consistency at the end of the data collection date.

\section{Data processing and analysis}

The data were coded and entered into Epi-Info version 7. Then, it was exported to SPSS version 20.0 and checked for a missing value. The normality of data was checked by the Kolmogorov-Smirnov test. Multicollinearity was checked by variance inflation factors (VIF) test. Factor analysis was conducted to identify variables that explained high variability among nutrition knowledge responses. The result was summarized using frequency, mean, standard deviation and percentage. Bivariate logistic regression analysis was conducted to identify variables associated with dietary practice and undernutrition of pregnant women. One independent variable at a time entered to check associated with the dependent variable in bivariate analysis. Variables with a $p$-value of less than 0.2 in the bivariate logistic regression analysis were entered into a multiple logistic regression model to control confounders. The forward model selection method was employed in multiple logistic regression. At $95 \%$ confidence, variable with probability value ( $p$-value) less than 0.05 was considered statistically significantly associated with dietary practice and nutritional status. The strength and direction of association were described using a crude odds ratio (COR) and adjusted odds ratio (AOR).

\section{Operational definitions}

Good nutrition knowledge: women had good nutritional knowledge if she scored greater than or equal to mean. 
Poor nutrition knowledge: women had poor nutritional knowledge if she scored less than mean.

Poor dietary practice: women had poor dietary practice if she scored less than $75 \%$ for dietary practice questions.

Good dietary practice: women had good dietary practice if she scored at least $75 \%$ for dietary practice questions $[19,20]$.

Poor perceived health belief (poorly perceived severity, susceptibility, benefits, and self-efficacy): a woman had poorly perceived health belief if she scored below mean.

Good perceived health belief (good perceived severity, susceptibility, exhibitions, and self-efficacy): a woman had good perceived health belief if she scored at least mean.

Poorly perceived barrier: a woman had poorly perceived barrier if she scored greater or equal to mean.

Good perceived barrier: a woman had good perceived barrier if she scored below the mean.

\section{Result}

Socio-demographic and economic characteristics of study participants

Socio-demographic and economic characteristics of the study participants were depicted in Table 1 . Six hundred four (604) pregnant women were participated in this study making a response rate of $100 \%$.

\section{Pregnancy and nutrition-related characteristics of the study participants}

Pregnancy and nutrition-related characteristics of the study participants are described in Table 2. About 348 (57.6\%) of pregnant women were in the third trimester. About 411 (68.05\%) had good nutritional knowledge, 428 (70.9\%) practice good hygiene. On the other hand, 93 (15.4\%) had been sick 2 weeks before the date of the survey.

\section{Women dietary diversity score}

Nearly one-fourth (25.5\%) of pregnant women had low dietary diversity and three fourth $(74.5 \%)$ had good dietary diversity (Table 3$)$. All (100\%) of pregnant women were consumed cereal, roots and tubers $24 \mathrm{~h}$ prior to the time of data collection. Almost all (99\%) were ate legumes 1 day before survey. Animal source foods such as meat/fish and poultry were consumed by nearly one fourth of participants and egg was consumed by $29.1 \%$ of pregnant women.

\section{Perceived health belief model constructs score}

The result of perceived susceptibility to malnutrition, perceived severity to malnutrition, perceived benefits of practicing good nutrition, perceived barriers to practice good nutrition and self-efficacy to improve malnutrition and practice good nutrition is indicated in Table 4 . About $78.3 \%$ of pregnant women perceived that they
Table 1 Socio-demographic and socio-economic characteristics of the pregnant women in Dessie town, northeastern Ethiopia, 2017 G.C, $(N=604)$

\begin{tabular}{|c|c|c|}
\hline Variables & Frequency & Percent \\
\hline \multicolumn{3}{|l|}{ Age of participants } \\
\hline$<25$ years $^{a}$ & 182 & 30.1 \\
\hline $26-35$ years & 264 & 43.7 \\
\hline$>35$ years & 158 & 26.2 \\
\hline \multicolumn{3}{|l|}{ Marital status } \\
\hline Unmarried & 170 & 28.1 \\
\hline Married & 434 & 71.9 \\
\hline \multicolumn{3}{|l|}{ Ethnicity } \\
\hline Amhara & 325 & 56.8 \\
\hline Afar & 122 & 20.2 \\
\hline Tigray & 101 & 16.7 \\
\hline Oromo & 56 & 9.3 \\
\hline \multicolumn{3}{|l|}{ Religion } \\
\hline Orthodox & 370 & 53.8 \\
\hline Muslim & 154 & 25.5 \\
\hline Protestant & 80 & 13.2 \\
\hline \multicolumn{3}{|l|}{ Head of house hold } \\
\hline Father & 377 & 62.4 \\
\hline Mother & 181 & 30.0 \\
\hline Others & 46 & 7.6 \\
\hline \multicolumn{3}{|c|}{ Educational status of the participants } \\
\hline No formal education & 182 & 30.1 \\
\hline Some education & 422 & 69.9 \\
\hline \multicolumn{3}{|l|}{ Family income } \\
\hline$<600$ ETB & 183 & 30.3 \\
\hline 601-1500ЕТВ & 224 & 37.1 \\
\hline$>1500 \mathrm{ETB}$ & 197 & 32.6 \\
\hline \multicolumn{3}{|l|}{ Cash decision maker } \\
\hline Father alone & 188 & 31.1 \\
\hline Mother alone & 134 & 22.2 \\
\hline Father and mother & 282 & 46.7 \\
\hline \multicolumn{3}{|l|}{ Family size } \\
\hline$\leq 4$ person & 379 & 62.7 \\
\hline$>4$ person & 225 & 37.3 \\
\hline \multicolumn{3}{|l|}{ Household facilities } \\
\hline No radio/television & 86 & 14.2 \\
\hline Radio/television & 518 & 85.8 \\
\hline \multicolumn{3}{|c|}{ Occupation of the head of household } \\
\hline Not employed & 148 & 24.5 \\
\hline Government employed & 182 & 30.1 \\
\hline Pretty trader & 89 & 14.7 \\
\hline Laborer & 79 & 13.1 \\
\hline Others** & 106 & 17.6 \\
\hline
\end{tabular}

${ }^{a}$ The study did not include women below 18 years old since it is difficult to take consent from under 18 years; ${ }^{* *}=$ non-governmental organization employed and students 
Table 2 Pregnancy and nutrition related characteristics of the study participants in Dessie town, northeastern Ethiopia, 2017 G.C, $(N=604)$

\begin{tabular}{|c|c|c|}
\hline Variables & Frequency & Percentage \\
\hline \multicolumn{3}{|l|}{ Stage of pregnancy } \\
\hline First trimester & 131 & 21.7 \\
\hline Second trimester & 125 & 20.7 \\
\hline Third trimester & 348 & 57.6 \\
\hline \multicolumn{3}{|c|}{ Have sources of nutrition information } \\
\hline Yes & 445 & 73.7 \\
\hline No & 159 & 26.3 \\
\hline \multicolumn{3}{|l|}{ Attend antenatal care } \\
\hline Yes & 427 & 70.7 \\
\hline No & 177 & 29.3 \\
\hline \multicolumn{3}{|c|}{ Take iron folic acid supplementation } \\
\hline Yes & 418 & 69.2 \\
\hline No & 186 & 30.8 \\
\hline \multicolumn{3}{|c|}{$\begin{array}{l}\text { Reasons for not taking iron/folic acid } \\
\text { supplement }\end{array}$} \\
\hline Bad taste & 62 & 10.3 \\
\hline III complications & 27 & 4.5 \\
\hline May harm child & 25 & 4.1 \\
\hline $\begin{array}{l}\text { Don't know iron/folic acid } \\
\text { supplements }\end{array}$ & 27 & 4.5 \\
\hline Other reasons & 27 & 7.5 \\
\hline \multicolumn{3}{|l|}{$\begin{array}{l}\text { Frequency of iron/folic acid } \\
\text { supplement intake }\end{array}$} \\
\hline Always & 308 & 51.0 \\
\hline Occasionally & 110 & 18.2 \\
\hline \multicolumn{3}{|l|}{ Have good nutrition knowledge } \\
\hline Yes & 411 & 68.05 \\
\hline No & 193 & 31.95 \\
\hline \multicolumn{3}{|c|}{ Practice good hygiene and sanitation } \\
\hline Yes & 428 & 70.9 \\
\hline No & 176 & 29.1 \\
\hline \multicolumn{3}{|c|}{ Sick in past 2 weeks prior to date of survey } \\
\hline Yes & 93 & 15.4 \\
\hline No & 511 & 84.6 \\
\hline
\end{tabular}

are susceptible to malnutrition and $60.3 \%$ perceived that malnutrition is severe for pregnant women and her fetus leading to health problems and death. About $83.9 \%$ of the participants perceived that practicing good nutrition has benefits in preventing malnutrition, $60.4 \%$ of participants had good perception towards barriers to practice good nutrition and prevent malnutrition and $81.5 \%$ had good perceived self-efficacy to practice good nutrition and prevent malnutrition.
Table 3 Women dietary diversity of the pregnant women in Dessie town, northeastern Ethiopia, 2017G.C, $(N=604)$

\begin{tabular}{ll}
\hline Food groups* $^{*}$ & Frequency (percentage) \\
\hline Cereals, white root and tubers, and plantains & $100(100.0)$ \\
Pulses/legumes & $598(99.0)$ \\
Nuts and seeds & $69(11.4)$ \\
Meat, fish and poultry (chicken) & $158(26.2)$ \\
Dairy and products & $154(25.5)$ \\
Egg & $176(29.1)$ \\
Dark green leafy vegetables & $280(46.4)$ \\
Other Vitamin A fruits and vegetables & $145(24.0)$ \\
Other fruits & $290(48.0)$ \\
Other vegetables & $312(51.6)$ \\
Women Dietary diversity & \\
Good (ate $\geq 5$ food groups) & $450(74.5)$ \\
Low/Poor (ate < 5 food groups) & $154(25.5)$ \\
\hline
\end{tabular}

\section{The dietary practice of pregnant women}

The result indicated that 273 (45.2\%) of pregnant women had good dietary practice while the rest 331 (54.8\%) had poor dietary practice. Specific dietary practice related activates are depicted in Table 5.

\section{Factors associated with the dietary practice}

Factors associated with the dietary practice of pregnant women depicted in Table 6. Pregnant women at first trimester were nearly half less likely to have poor dietary

Table 4 Perceived Health belief model constructs score of pregnant women in Dessie town, northeastern Ethiopia, 2017G.C, $(N=604)$

\begin{tabular}{lll}
\hline Variables & Frequency & Percentage \\
\hline Perceived susceptibility & to malnutrition & \\
Good & 473 & 78.3 \\
Poor & 131 & 21.7
\end{tabular}

Perceived severity to malnutrition

$\begin{array}{lll}\text { Good } & 364 & 60.3 \\ \text { Poor } & 240 & 39.7\end{array}$

Perceived benefits of good nutrition

$\begin{array}{lll}\text { Good } & 480 & 79.47 \\ \text { Poor } & 124 & 20.53\end{array}$

Perceived barriers to practice good nutrition

$\begin{array}{lll}\text { Good } & 365 & 60.4 \\ \text { Poor } & 239 & 39.6\end{array}$

Perceived self efficacy to prevent malnutrition and practice good nutrition

\begin{tabular}{lll} 
Good & 492 & 81.5 \\
Poor & 112 & 18.5 \\
\hline
\end{tabular}


Table 5 Frequency and percent of specific dietary practice related variables among pregnant women in Dessie town, northeastern Ethiopia, 2017 G.C, $(N=604)$

\begin{tabular}{|c|c|c|}
\hline Variables & Frequency & Percent \\
\hline \multicolumn{3}{|c|}{ Crave food not normally consumed* } \\
\hline Yes & 278 & 46 \\
\hline \multicolumn{3}{|c|}{ Avoid any food items during current pregnancy* } \\
\hline Yes & 354 & 58.6 \\
\hline \multicolumn{3}{|l|}{ Reason of avoiding food items } \\
\hline Personal dislike & 179 & 29.6 \\
\hline Religion & 39 & 6.5 \\
\hline Makes fetus big & 17 & 2.8 \\
\hline Culture & 15 & 2.5 \\
\hline \multicolumn{3}{|l|}{ Follow specific dietary regime* } \\
\hline Yes & 225 & 37.3 \\
\hline \multicolumn{3}{|l|}{ Meal frequency } \\
\hline$<3$ meals & 284 & 47 \\
\hline 3 meals & 320 & 53 \\
\hline \multicolumn{3}{|c|}{ Eat snack between meals during current pregnancy* } \\
\hline Yes & 439 & 72.7 \\
\hline \multicolumn{3}{|c|}{ Skipping any meal during current pregnancy* } \\
\hline Yes & 131 & 21.7 \\
\hline \multicolumn{3}{|l|}{ Skipped Which meals } \\
\hline Dinner & 68 & 11.3 \\
\hline Breakfast & 61 & 10.1 \\
\hline Lunch & 2 & 0.3 \\
\hline \multicolumn{3}{|c|}{ Eat protein rich foods during current pregnancy ${ }^{a}$} \\
\hline Yes & 487 & 80.6 \\
\hline \multicolumn{3}{|c|}{ Habits of eating fresh fruits and vegetables ${ }^{a}$} \\
\hline Yes & 475 & 78.6 \\
\hline \multicolumn{3}{|l|}{ Use iodized salt $^{\mathrm{a}}$} \\
\hline Yes & 564 & 93.4 \\
\hline \multicolumn{3}{|c|}{ Time of adding salt into cooking food } \\
\hline At the end of cooking & 376 & 62.2 \\
\hline At the middle of cooking & 76 & 12.6 \\
\hline At the beginning of cooking & 146 & 24.2 \\
\hline Cook without any salt & 6 & 1.0 \\
\hline \multicolumn{3}{|l|}{ Amount of fluid drunk per day } \\
\hline Less than a liter & 358 & 59.3 \\
\hline $1-1.5 \mid$ & 168 & 27.8 \\
\hline More than 1.51 & 78 & 12.9 \\
\hline \multicolumn{3}{|l|}{ Include the following in fluid } \\
\hline Milk & 92 & 15.2 \\
\hline Fruit juice & 83 & 13.7 \\
\hline Soup & 141 & 23.3 \\
\hline Herbal tea & 288 & 47.8 \\
\hline \multicolumn{3}{|c|}{ Follow weight gain during current pregnancy } \\
\hline Yes & 281 & 46.5 \\
\hline
\end{tabular}

${ }^{a}$ The remaining numbers (frequency) of participants belongs to "No" response practice as compared to the third trimester $(\mathrm{AOR}=0.46$; $95 \% \mathrm{CI}=0.26,0.80)$. Women with no history of illness 2 weeks before the date of the survey were 0.42 times less likely to have poor dietary practice compared to their counterparts (AOR $=0.42$; 95\% CI: $0.22,0.80$ ). The poor dietary practice was $63 \%$ higher among women who perceived poorly to the severity of malnutrition compared to women who perceived malnutrition as severe $(\mathrm{AOR}=$ 1.64; 95\% CI: 1.15, 2.33). Women having poor selfefficacy to practice good nutrition were $4.74(\mathrm{AOR}=$ 4.74; 95\% CI: $2.94,7.65)$ times more likely to practice poor nutrition than their counterparts. Similarly, the odds of practicing poorly was $63 \%$ higher $(\mathrm{AOR}=1.63$; $95 \% \mathrm{CI}=1.14,2.32$ ) among pregnant women who poorly perceiving benefits of practicing appropriate nutrition.

\section{Factors associated with nutritional status of pregnant women}

The result of factors associated with nutritional status revealed that 118 (19.5\%) of pregnant women were undernourished (MUAC $<23 \mathrm{~cm}$ ) and the rest 486 $(80.5 \%)$ were normal (MUAC $\geq 23 \mathrm{~cm}$ ). Antenatal care (ANC) follow-up, history of illness, dietary diversity, nutritional knowledge, good dietary practice, and perceived self-efficacy to prevent malnutrition were showed significant association with undernutrition (Table 7). Accordingly, pregnant women who did not follow ANC during the current pregnancy were 3.46 times more likely to be undernourished than their counterparts $(\mathrm{AOR}=3.46$; $95 \%$ CI: $2.07,5.78$ ). Undernutrition was $93 \%$ higher in women who had a history of illness in the past 2 weeks before the survey date (AOR $=1.93 ; 95 \% \mathrm{CI}: 1.10,3.52)$. Women with poor dietary diversity $(\mathrm{DDS}<5)$ were 5.92 times more likely to be undernourished $(\mathrm{AOR}=5.92$; 95\% CI: $3.59,9.76)$ compared to women having good dietary diversity. Undernutrition among women with poor nutritional knowledge and poor dietary practice was $3.03(\mathrm{AOR}=3.03 ; 95 \% \mathrm{CI}: 1.87,4.92)$ and 3.25 $(\mathrm{AOR}=3.25 ; 95 \% \mathrm{CI}: 1.91,5.54)$ times higher compared to their respective counterparts, respectively. Women having poor self-efficacy to practice appropriate nutrition and improve malnutrition were 5.59 times more likely to be undernourished ( $\mathrm{AOR}=5.59 ; 95 \% \mathrm{CI}$ : 3.56 , 8.79) compared to women with good perceived selfefficacy.

\section{Discussion}

Poor dietary practice and undernutrition among pregnant women have a major impact on fetus health and development. Nutrition of pregnant women should supply a sufficient amount of nutrients for mother, fetus and for successful lactation [21]. Various factors can influence dietary practice and nutritional status leading to poor pregnancy outcomes. The objective of this study 
Table 6 Factors associated with dietary practice of pregnant women in Dessie town, northeastern Ethiopia, 2017 G.C, (N =604)

\begin{tabular}{|c|c|c|c|c|c|}
\hline \multirow[t]{2}{*}{ Variables } & \multicolumn{2}{|c|}{ Dietary practice $(\mathrm{n})$} & \multirow[t]{2}{*}{ COR $(95 \% \mathrm{Cl})$} & \multirow[t]{2}{*}{ AOR $(95 \% \mathrm{Cl})$} & \multirow[t]{2}{*}{$p$-value } \\
\hline & Poor & Good & & & \\
\hline \multicolumn{6}{|l|}{ Stage of pregnancy } \\
\hline First trimester & 54 & 77 & $0.53(0.35,0.79)$ & $0.46(0.26,0.80)$ & 0.016 \\
\hline Second trimester & 78 & 47 & $1.24(0.82,1.89)$ & $0.92(0.53,1.62)$ & 0.78 \\
\hline Third trimester & 119 & 149 & 1 & 1 & \\
\hline \multicolumn{6}{|l|}{ History of sickness } \\
\hline No & 266 & 245 & $0.47(0.29,0.75)$ & $0.42(0.22,0.80)$ & 0.01 \\
\hline Yes & 65 & 28 & 1 & 1 & \\
\hline \multicolumn{6}{|c|}{ Perceived severity to malnutrition } \\
\hline Poor & 134 & 106 & $2.05(1.47-2.85)$ & $1.64(1.15,2.33)$ & 0.006 \\
\hline Good & 139 & 225 & 1 & 1 & \\
\hline \multicolumn{6}{|c|}{ Perceived benefits of good nutritional practice } \\
\hline Poor & 119 & 105 & $1.66(1.19-2.32)$ & $1.63(1.14,2.32)$ & 0.007 \\
\hline Good & 154 & 226 & 1 & 1 & \\
\hline \multicolumn{6}{|c|}{ Perceived self efficacy to control malnutrition } \\
\hline Poor & 85 & 27 & $5.09(3.18-8.14)$ & $4.74(2.94,7.65)$ & $<0.001$ \\
\hline Good & 188 & 304 & 1 & 1 & \\
\hline
\end{tabular}

AOR Adjusted Odds Ratio, COR Crude Odds Ratio, Cl Confidence Interval

was to determine factors associated with dietary practice and the nutritional status of pregnant women in Dessie town, northeastern Ethiopia. The overall dietary practice implies that maternal nutritional practice is sub-optimal in Ethiopia though health sectors developing different health and nutrition intervention programs.

The result revealed that $54.8 \%$ of the pregnant women had poor dietary practice and $19.5 \%$ were undernourished. The magnitude of poor dietary practice in this study is lower than $66.2 \%$ that was reported in the Oromiya region of western Ethiopia [13] and 59.9\% reported in the Amhara region of northwestern Ethiopia [22]. Another crosssectional study conducted by Amanuel and Tona (2018), in Bahirdar town, North West Ethiopia explored a higher prevalence $(60.7 \%)$ of poor dietary practice [9]. This variation might be due to differences in a geographical area, agro-economic practices, the specific culture of a community, an individual's dietary preference and seasonal variation in food production and consumption. On the other hand, agricultural food production practice varies across different geographic locations of Ethiopia. For instance, southern parts of Ethiopia produce mostly root and tuber crops, fruits and vegetables while northern parts of Ethiopia produce and depend on cereal crops. Ethiopia also has diverse religion followers. These factors are possibly caused variation in dietary practice.

Regarding specific dietary practices, about $47 \%$ of pregnant women had meal frequency less than three per day and $58.6 \%$ were avoided at least one food item during the current pregnancy. The main reason for avoiding food items was personal dislike, religion, belief that it makes the fetus big and culture. These reasons are in agreement with the study reported in northwestern Ethiopia [9]. The prevalence of pregnant women avoided food items in this study is higher than the study reported in southern Ethiopia where $21 \%$ of pregnant women avoided at least one food item [23]. The result of avoiding food items and meal frequency in this study is inconsistent with a study reported from the Oromiya region of Ethiopia where $35.8 \%$ of pregnant women were avoided at least one food item and $66.1 \%$ had meal frequency less than three times per day [13]. Another study from Addis Ababa, Ethiopia, illustrated that about 27.3\% of pregnant women were avoided at least one food item during pregnancy [24]. This variation in the prevalence of good and poor dietary practices compared to another similar study might be duet individual difference in perception towards food and nutrient intake, household food security status and individual pregnancy-related complications. The difference might also be due to variation in socio-economic and socio-demographic factors; and cultural differences since research evidence suggests that dietary preferences could be influenced by cultural, social, economic and environmental determinants $[24,25]$.

In this study, $19.5 \%$ of pregnant women were undernourished (MUAC $<23 \mathrm{~cm}$ ). The result is consistent with finding from Kenya where $19.3 \%$ of pregnant women were undernourished [26]. On the contrary, the result of the present study is higher than the study reported in 
Table 7 Factors associated with nutritional status of pregnant women in Dessie town, northeastern Ethiopia, 2017 G.C, (N=604)

\begin{tabular}{|c|c|c|c|c|c|}
\hline \multirow[t]{2}{*}{ Variables } & \multicolumn{2}{|l|}{ Nutritional status } & \multirow[t]{2}{*}{ COR $(95 \% \mathrm{Cl})$} & \multirow[t]{2}{*}{ AOR $(95 \% \mathrm{Cl})$} & \multirow[t]{2}{*}{$p$-value } \\
\hline & Undernourished & Normal & & & \\
\hline \multicolumn{6}{|l|}{ Attend ANC } \\
\hline No & 69 & 108 & $4.93(3.22,7.53)$ & $3.46(2.07,5.78)$ & $<0.001$ \\
\hline Yes & 49 & 378 & 1 & 1 & \\
\hline \multicolumn{6}{|l|}{ History of sickness } \\
\hline Yes & 33 & 60 & $2.75(1.69,4.47)$ & $1.93(1.10,3.52)$ & 0.033 \\
\hline No & 85 & 426 & 1 & 1 & \\
\hline \multicolumn{6}{|l|}{ Dietary diversity } \\
\hline Poor $(<5)$ & 69 & 85 & $6.64(4.30,10.26)$ & $5.92(3.59,9.76)$ & $<0.001$ \\
\hline Good $(\geq 5)$ & 49 & 401 & 1 & 1 & \\
\hline \multicolumn{6}{|c|}{ Nutritional knowledge } \\
\hline Poor & 72 & 121 & $4.72(3.09,7.21)$ & $3.03(1.87,4.92)$ & $<0.001$ \\
\hline Good & 46 & 365 & 1 & 1 & \\
\hline \multicolumn{6}{|l|}{ Dietary practice } \\
\hline Poor & 77 & 254 & $1.72(1.13,2.60)$ & $3.25(1.91,5.54)$ & $<0.001$ \\
\hline Good & 41 & 232 & 1 & 1 & \\
\hline \multicolumn{6}{|c|}{ HBM (perceived self efficacy) } \\
\hline Negative/Poor & 52 & 60 & $5.59(3.56,8.79)$ & $5.59(3.56,8.79)$ & $<0.001$ \\
\hline Positive/good & 66 & 426 & 1 & 1 & \\
\hline
\end{tabular}

AOR Adjusted Odds Ratio, COR Crude Odds Ratio, Cl Confidence Interval

china where $11.8 \%$ of pregnant women were undernourished [14]. Another study from the northern part of Ethiopia also indicated a lower prevalence (16.2\%) compared to this study [9]. Similarly, a lower prevalence of undernutrition (15.2\%) among pregnant women was explored in the Dale district of southern Ethiopia [10]. However, the prevalence of undernutrition in this study is lower than 32\% reported in Bangladesh [27], and 35.5\% reported in Boricha district of southern Ethiopia [11]. These variations might be attributed by the difference in stage of pregnancy, nutritional practice, a seasonal variation on food consumption and the use of different cut off points for mid-upper arm measurement in different studies.

History of illness 2 weeks before the date of data collection showed a negative association with poor dietary practice. This is unlikely but might be due to increased appetite and food requirements during the recovery period from illness. This might be made individuals follow the appropriate dietary practice. The finding of this study contradicts a study conducted in northern Ethiopia which indicated that the history of illness was positively associated with poor dietary practice [9]. This might be due to differences in types and severity of illness in two population groups. Being in the first trimester was negatively associated with the poor dietary practice. This might be due to the increased physiological demand for body nutrients in the first trimester made women practice good nutrition than practicing poor nutrition. The Health Belief Model (HBM) is one of the well-accepted models that refer to the key role of people's beliefs. When people understand the level of risk that an unhealthy behavior poses and their susceptibility to the adverse consequences of their feelings, they become interested in methods that reduce their health and nutrition risks. In this study, poorly perceived severity of malnutrition, poor perceived benefits of practicing appropriate nutrition and poorly perceived self-efficacy to practice appropriate nutrition were associated with the poor dietary practice. This might be explained by that pregnant women did not fear for the severity of malnutrition, did not understand the benefits of practicing good nutrition for the fetus and herself, and unable to practice appropriate nutrition had a high chance to follow the poor dietary practice.

Not following antenatal care (ANC) during the current pregnancy was positively associated with undernutrition. This might be explained by when pregnant women attend ANC; they get nutrition information from health professionals and follow the healthy dietary practice. This is also in agreement with other finding such that women exposed to nutrition information were more likely to practice good dietary practice [23]. Following healthy nutrition further, improve nutrient intake and improve nutritional status. Women with a history of illness showed greater odds of being undernourished. This 
can be due to that there is a synergetic effect between malnutrition and illness such that illness increased energy and nutrient demand while decreasing food intake. This had resulted in women undernutrition. Dietary diversity also associated with nutritional status. This finding supported by a study conducted in Kenya in which dietary diversity was positively correlated with pregnant women's nutritional status [26]. Similarly, a study in Pakistan illustrated that dietary diversity was significantly associated with a weight gain of pregnant women [28]. This might be because of as more food groups included in a daily diet, the greater the chances of meeting nutrient requirements by improving nutritional status [29]. On the other hand, different scholars demonstrated that dietary diversity is indeed associated with nutrient adequacy [30-32].

Poor nutritional knowledge and poor dietary practice were positively associated with maternal undernutrition. The odds of undernutrition among women with poor dietary knowledge and poor dietary practice were higher than their counterparts. This could be possibly due to that when a woman had poor nutritional knowledge, she became less focused on good dietary practice and not put it into practice. Besides, poor nutritional knowledge about basic nutrients and a balanced diet usually result in poor dietary practice leading to undernutrition. Not engaging in appropriate dietary practice contributes to low dietary diversity and nutrition intake leading undernutrition. Among dietary perceptions, women who perceived positive, confident and able to follow good nutritional practice (self-efficacy) had lower odds of undernutrition.

\section{Conclusion}

The prevalence of poor dietary practice among pregnant women was $54.8 \%$ and undernutrition was $19.5 \%$ indicating that dietary practice is suboptimal and undernutrition is relatively high. Being first at trimester of pregnancy, history of illness, perceived severity to malnutrition, perceived benefits and self-efficacy were associated with the poor dietary practice. ANC attendance, history of illness, dietary diversity, poor nutritional knowledge, poor dietary practice and poorly perceived self-efficacy were significantly associated with undernutrition.

\section{Recommendations}

Government, health extension workers and other concerned bodies should encourage pregnant women to attend ANC, prevent sickness and promote health during pregnancy, strength, and counsel to improve dietary diversity and practice good nutrition. Special focus should be given as a stage of pregnancy increase particularly in at third trimester. They should focus on the perceived belief of dietary behaviors particularly perceives the severity of pregnant women and fetuses to malnutrition, perceived benefits of practicing good nutrition and perceived self-efficacy to practice good nutrition and prevent malnutrition. This advice is for a similar situation in Ethiopia since the data in this study only apply to similar populations, but not places outside of Ethiopia or major urban areas.

\section{Limitation of the study}

The current study did not evaluate food insecurity as a factor in maternal dietary practice and nutritional status though it is an underlying cause of malnutrition.

\section{Abbreviations \\ AOR: Adjusted Odds Ratio; Cl: Confidence Interval; COR: Crude Odds Ratio; DDS: Dietary Diversity Score; ETB: Ethiopian Birr; G.C: Gregorian calendar; HBM: Health Belief Model; MUAC: Mid Upper Arm Circumference}

\section{Acknowledgments}

The researcher gratefully thanks Wollo University for funding this research. I would like also to thank Dessie town administration and health department for allowing me to conduct this research in the community. Finally, I highly acknowledge study participants for providing all necessary information and data collectors.

\section{Authors' contributions}

The author of this manuscript designed a study, carried out data collection, data management, analysis and interpretation and prepared manuscript. The author read and approved the final manuscript.

\section{Funding}

This study was conducted by getting the fund from Wollo University. I declare that the funding body had no role in the design of the study, the collection, analysis and interpretation of the data, the writing of this manuscript, and the decision to submit it for publication.

\section{Availability of data and materials}

The datasets used and analyzed for this study available from the corresponding author on reasonable request.

\section{Ethics approval and consent to participate}

Ethical approval was obtained from Wollo University ethical review committee. Permission was obtained from Dessie town administration public health office. Written consent was obtained from each study participant before starting data collection.

Consent for publication

Not applicable.

Competing interests

The author declares that I have no competing interests.

Received: 6 September 2018 Accepted: 28 November 2019

Published online: 23 December 2019

\section{References}

1. Bhutta ZA, Das JK, Rizvi A, et al. Evidence-based interventions for improvement of maternal and child nutrition: what can be done and at what cost? Lancet. 2013;382(9890):452-77.

2. Black RE, Allen LH, Bhutta ZA, Caulfield LE, de Onis M, al EMe. Maternal and child undernutrition: Global and regional exposures and health consequences Lancet 2008(371):243-260.

3. ACC/SCN. Symposium Report on a Nutrition Policy Discussion Paper on Women and Nutrition: Geneva. 1990;6:27-31.

4. Christian P, West KP, Khartry SK, et al. Night blindness of pregnancy in rural Nepal: nutritional and health risks. Int J Epidemiol. 1998;27:231-7.

5. Kramer MS. Determinants of low birth weight: methodological assessment and meta-analysis. Bull World Health Organ. 1987;65:663-737. 
6. World Health Organization (WHO). WHO Recommendations on Interventions to Improve Preterm Birth Outcomes. Geneva: WHO. 2015.

7. World Health Organization (WHO). Comprehensive Implementation Plan on Maternal, Infant and Young Child Nutrition. Geneva: WHO. 2014

8. Central Statistical Agency [Ethiopia] and ICF International: Ethiopia Demographic and Health Survey. Addis Ababa, Ethiopia, and Calverton. Maryland, USA: Central Statistical Agency and ORC Macro; 2016. p. 2017.

9. Nana A, Zema T. Dietary practice and associated factors during pregnancy in northwestern Ethiopia. BMC Pregnancy and Childbirth. 2018;18(183).

10. Kuche D, Singh P, Moges D, Belachew T. Nutritional status and associated factors among pregnant women in Wondo Genet District, southern Ethiopia. J Food Sci Eng. 2015:85-94.

11. Moges M, Worku A, Loha E. Nutritional status and associated factors among pregnant women in Boricha Woreda, Sidama zone, southern Ethiopia. Eur J Nutrition and Food Safety. 2015;5:2347-5641.

12. Madhavi LH, Singh HKG. Nutritional status of rural pregnant women. People's J Sci Res. 2011;4(2):20-3.

13. Mekonnen S.A, Endalamaw M.T. Dietary Practice and Associated Factors among Pregnant Women in Gondar Town North West, Ethiopia. Int J Nutrition and Food Sci. 2015;4(6):707-712. doi: 7https://doi.org/10.11648/j. ijnfs.20150406.20150427

14. Veronika S, Hans Konrad B, Qi Wang HE, Anne C. Bellows: dietary intake and food habits of pregnant women residing in urban and rural areas of Deyang City, Sichuan Province, China. Nutrients. 2013;5:2933-54.

15. Teller H, Yimar G. Levels and determinants of malnutrition in adolescent and adult women in southern Ethiopia. Ethiop J Health Dev. 2000;14(1):57-66.

16. Central Statistical Authority [Ethiopia] and ORC Macro: Ethiopia Demographic and Health Survey. Addis Ababa, Ethiopia, and Calverton. Maryland: Central Statistical Authority and ORC Macro; 2000. p. 2001.

17. FAO and FHI 360. Minimum Dietary Diversity for Women: A Guide for Measurement. Rome: FAO. 2016.

18. Tang, A.M. et al. Determining a Global Mid-Upper Arm Circumference Cutoff to Assess Malnutrition in Pregnant Women. Washington, DC: FHI 360/Food and Nutrition Technical Assistance III Project (FANTA). 2016.

19. Shehab L. Nutritional Awareness of Women during Pregnancy. J American Sci. 2012;8(7).

20. Shahid Mahrnood MFA SS, Azhar Mujeeb, Naira Bano, Mubasher H. Assessment of Nutritional Beliefs and Practice in Pregnant and Lactating Mothers in an Urban and Rural Area of Pakistan 2015:60-2.

21. Hoffmann JF, Nunes MAA, Schmidt MI, Olinto MTA, Melere C, Ozcariz SGl ea. . Dietary patterns during pregnancy and the association with sociodemographic characteristics among women attending general practice in southern Brazil: the ECCAGe Study. Cadernos de saude publica 2013;29(5):970-980.

22. Daba G, Beyene F, Fekadu H, Garoma W. Assessment of nutritional practice of pregnant mothers on maternal nutrition and associated factors in Guto Gida Woreda, east Wollega zone. Ethiopia Sci Technol Arts Res J. 2013;2(3): 105-13.

23. Kuche D, Singh $P$, Moges D. Dietary practice and associated factors among pregnant women in Wondo Genet District, southern Ethiopia. J Pharm and Sci Innov. 2015;4(5):270-5.

24. Zelalem A, Endeshaw M, Ayenew M, Shiferaw S, Yirgu R. Effect of nutrition education on pregnancy specific nutrition knowledge and healthy dietary practice among pregnant women in Addis Ababa. Clinics Mother Child Health. 2017:14:265. https://doi.org/10.4172/2090-7214.1000265.

25. Krondl M, Coleman P. Social and biocultural determinants of food selection. Prog Food Nutr Sci. 1986:10:179-203.

26. Willy K, Judith K, Peter C. Dietary Diversity, Nutrient Intake and Nutritional Status among Pregnant Women in Laikipia County, Kenya. International Journal of Health Sciences \& Research. 2016;6(4).

27. Hossain B, Sarwar T, Reja S, Akter MN. Nutritional status of pregnant women in selected rural and urban area of Bangladesh. J Nutr Food Sci. 2013;3:219.

28. Ali F, Thaver I, Khan SA. Assessment of dietary diversity and nutritional status of pregnant women in Islamabad. Pakistan Ayub Med Coll Abbottabad. 2014;26(4):506-9.

29. The Sphere Project. Humanitarian charter and minimum standards in humanitarian response, chapter 3: minimum standards in food security and nutrition. Geneva: The Sphere Project; 2011.
30. Lee SE, Talegawkar SA, Merialdi M, Caulfield LE. Dietary intakes of women during pregnancy in low- and middle-income countries Public Health Nutrition 2013;16(08):1340-53.

31. Jayawardena R, Byrne NM, Soares MJ, Katulanda P, Yadav B, Hills AP. High dietary diversity is associated with obesity in Sri Lankan adults: an evaluation of three dietary scores. BMC Public Health. 2013;13(1):314.

32. Ruel MT. Operationalizing dietary diversity: a review of measurement issues and research priorities. J Nutr. 2003;133(11):3911S-26S.

\section{Publisher's Note}

Springer Nature remains neutral with regard to jurisdictional claims in published maps and institutional affiliations.
Ready to submit your research? Choose BMC and benefit from:

- fast, convenient online submission

- thorough peer review by experienced researchers in your field

- rapid publication on acceptance

- support for research data, including large and complex data types

- gold Open Access which fosters wider collaboration and increased citations

- maximum visibility for your research: over $100 \mathrm{M}$ website views per year

At $\mathrm{BMC}$, research is always in progress.

Learn more biomedcentral.com/submissions 